\title{
Diagnostic accuracy of blood sucrose as a screening test for equine gastric ulcer syndrome (EGUS) in adult horses
}

Michael Hewetson ${ }^{1,4^{*}}$, Ben William Sykes ${ }^{2}$, Gayle Davina Hallowell ${ }^{3}$ and Riitta-Mari Tulamo

\begin{abstract}
Background: Equine gastric ulcer syndrome (EGUS) is common in adult horses, particularly those involved in performance disciplines. Currently, detection of EGUS by gastroscopy is the only reliable ante mortem method for definitive diagnosis; however it is unsuitable as a screening test because it is expensive, time consuming, and is not readily available to most veterinarians. Sucrose permeability testing represents a simple, economical alternative to gastroscopy for screening purposes, and the feasibility of this approach in the horse has been previously reported. The aim of this study was to determine the diagnostic accuracy of blood sucrose as a screening test for EGUS in a large group of adult horses with and without naturally occurring gastric disease.

Results: One hundred and one adult horses with or without naturally occurring gastric ulceration were studied. The diagnostic accuracy of blood sucrose for diagnosis of gastric lesions (GL), glandular lesions (GDL), squamous lesions (SQL), and clinically significant lesions (CSL) at 45 and 90 min after administration of $1 \mathrm{~g} / \mathrm{kg}$ of sucrose via nasogastric intubation was assessed using receiver operator characteristics (ROC) curves and calculating the area under the curve (AUC). For each lesion type, sucrose concentration in blood was compared to gastroscopy, as the gold standard, and sensitivities (Se) and specificities (Sp) were calculated across a range of sucrose concentrations. Ulcer grading was performed blindly by one observer; and the results were validated by comparing them with that of two other observers, and calculating the level of agreement. Cut-off values were selected manually to optimize Se. The prevalence of GL, GDL, SQL, and CSL was 83, 70, 53 and 58\% respectively. At the selected cut-offs, Se ranged from 51 to $79 \%$ and Sp ranged from 43 to $72 \%$, depending upon the lesion type and time of sampling.

Conclusions: Blood sucrose is neither a sensitive or specific test for detecting EGUS in this population of adult horses with naturally occurring gastric ulceration. Further studies aimed at evaluating the performance characteristics of the test in different study populations are warranted. Given the limitations of endoscopy, due consideration should also be given to alternative methods for comparison of blood sucrose with a gold standard.
\end{abstract}

Keywords: Sucrose, Equine, Ulcer, Glandular, Squamous, EGUS, EGGD, ESGD, Permeability, Sensitivity, Specificity

\section{Background}

Equine gastric ulcer syndrome (EGUS) is a term used to describe erosive and ulcerative diseases of the equine stomach; and can be further classified into equine squamous gastric disease (ESGD) and equine glandular gastric disease (EGGD) based on the anatomical region

\footnotetext{
*Correspondence: michael.hewetson@up.ac.za

${ }^{4}$ Department of Companion Animal Clinical Studies, Faculty of Veterinary

Science, University of Pretoria, Onderstepoort, South Africa

Full list of author information is available at the end of the article
}

affected [1]. EGUS is common in horses and although the clinical ramifications of this disease have as yet, not been completely elucidated, it remains an important disease in the equine industry. Performance horses are particularly susceptible, with $47-100 \%$ of Thoroughbred racehorses [2-5], 44-87\% of Standardbred racehorses [6-8], $33-93 \%$ of endurance horses $[9,10]$ and $58-64 \%$ of show and sport horses $[11,12]$ found to have gastric lesions on gastroscopy. Non-performance horses are also susceptible to EGUS, with ulcers found in the gastric mucosa of 
$11-67 \%$ of sedentary horses and horses that partake in less strenuous activities [13-15].

Currently, detection of EGUS by gastroscopy is the only reliable ante mortem method for definitive diagnosis in horses [16] and is considered the gold standard against which all other diagnostic tests are compared [1]. Disadvantages of gastroscopy are that it's not readily available to most veterinarians, it is an inefficient expenditure of time, and it requires a minimum level of expertise to perform and interpret. Furthermore, gastroscopy is costly to the client and with an increase in public awareness of EGUS and its popularity as a 'catch-all' diagnosis for poor performance in sport horses, many owners are electing to treat their horses on an empirical basis without the benefit of a definite diagnosis. Given the current economic climate and the rising costs of omeprazole, it is easy then to imagine that owners and veterinarians would be interested in using an economical screening test to rule out gastric ulcers. Such a screening test should ideally have a high sensitivity as it will correctly identify most horses with gastric ulcers, remembering that many horses with EGUS will not demonstrate clinical signs, and are considered to have 'silent' or non-clinical gastric ulceration [14, 17-20].

Sucrose permeability testing represents a simple, economical alternative to gastroscopy for screening purposes, and the feasibility of this approach in the horse has been previously reported [21-23]. Because of its large molecular size (342 Da), sucrose is not able to permeate across healthy gastrointestinal mucosa, but it has been reported to cross the mucosa in the presence of gastrointestinal disease, presumably due to an changes in intestinal tight junction permeability or directly through gaps in the epithelium caused by erosion or ulceration [24-26]. The efficiency of the mucosal disaccharidases and the monosaccharide transport systems in the equine small intestine has been established by a series of oral disaccharide and monosaccharide tolerance tests, and it has been demonstrated that adult horses are fully capable of rapidly hydrolyzing sucrose [27, 28]. Furthermore, sucrase has the highest activity in the duodenum of the horse, with concentrations similar to those reported in the intestine of other non-ruminant species [29]. If present in blood, sucrose is cleared via the urine; it is not metabolized and the body does not produce it [30, 31]. Therefore, increased amounts of sucrose in blood after an oral dose is site specific for increased gastric permeability, and can be used to predict the presence of gastric disease [32-38].

The objective of this study was to determine the diagnostic accuracy of blood sucrose as a potential screening test for EGUS in adult horses by comparing it to gastroscopy as the gold standard.

\section{Methods}

\section{Study design}

The study was conducted as a blind comparison to a gold standard.

\section{Study population}

One hundred and one adult horses were eligible for inclusion in the study and were recruited from horses that had been referred to the University of Helsinki Equine Teaching Hospital, Finland for gastroscopy and from a local riding center. The horses were used for a wide range of equestrian activities, ranging from dressage to racing, and were recruited on the assumption that up to $53 \%$ of them would be affected by naturally occurring gastric ulceration of EGUS severity score $\geq 2[14,16]$. Horses were excluded from the study if they had received nonsteroidal anti-inflammatory drugs or omeprazole within 7 days prior to testing. This was done to avoid confounding changes in gastric permeability secondary to administration of these drugs $[23,39,40]$.

\section{Gastroscopy}

Owners were asked to withhold food from their horses for $16 \mathrm{~h}$ and water for $6 \mathrm{~h}$ prior to sucrose testing. Following completion of fasting, blood samples $(10 \mathrm{ml})$ were collected in vacuumed clot tubes from the jugular vein; horses were sedated with a combination of intravenous detomidine hydrochloride $\left(10 \mu \mathrm{g} / \mathrm{kg}\right.$ body weight $(\mathrm{BW})^{1}$ and butorphanol $(0.025 \mathrm{mg} / \mathrm{kg} \mathrm{BW})^{2}$; and gastroscopy was performed using a previously described technique [21].

All endoscopic examinations were recorded and archived. For each horse, video recordings and still-frame images were taken of the stomach from the right side of the stomach along the margo plicatus, the dorsal part of the fundus, the greater curvature along the margo plicatus, the lesser curvature along the margo plicatus, the glandular mucosa in the region of the pylorus and the proximal duodenum [41].

\section{Administration of sucrose and collection of samples}

Immediately following gastroscopy, $1 \mathrm{~g} / \mathrm{kg} \mathrm{BW}$ of sucrose $^{3}$ was administered as a $10 \%$ solution via nasogastric tube to each horse. Blood samples $(10 \mathrm{ml})$ were then collected in vacuumed clot tubes from the jugular vein at 45 and 90 min after administration of sucrose. These time points were chosen based upon data from a previous study which indicated that peak sucrose concentrations occur approximately between 45 and 90 min after sucrose

\footnotetext{
${ }^{1}$ Domosedan, Elanco Animal Health, UK.

2 Butador, Chanelle Vet animal health, UK

3 Kidesokeri 530, Sucros Oy, Finland.
} 
administration [21]. Horses were not given access to food until the final blood sample had been collected to prevent ingestion of sucrose that may have been present in the food. Following blood collection, the serum was separated by centrifugation $(10 \mathrm{~min}$ at $2000 \times g)$ and then stored in a freezer at $-80^{\circ} \mathrm{C}$ until analysis.

\section{Lesion assessment}

Following completion of data collection, video recordings and still-frame images from each horse were reviewed independently by a board-certified internist (BS) who was blinded to the results of the sucrose assay. For each set of videos/images, the observer was asked to answer a set of dichotomous (yes or no) questions: does the horse have (1) gastric lesions? (2) glandular lesions? (3) squamous lesions? and (4) are the gastric lesions clinically significant? The term "gastric lesion" was used to describe lesions throughout the gastric mucosa and is synonymous with the term EGUS. In contrast, the terms "glandular lesion" and "squamous lesion" were used to differentiate the two different anatomical regions of the equine stomach and are synonymous with the term EGGD and ESGD respectively [1]. Clinically significant gastric lesions were used as a proxy indicator of ulcer severity and were defined as lesions that the observer would consider severe enough to warrant treatment. The term 'lesion' rather than 'ulceration' was used to enable the observer to report on the presence of other types of lesions (e.g. erosions) in addition to ulceration, as any damage to the mucosa of the stomach has the theoretical potential to increase permeability to sucrose [24-26].

\section{Inter-observer agreement}

In order to assess the validity of the gastroscopy assessment, the observations for each horse were compared with observations made by two other board certified internists on the same set of video recordings and still-frame images $(\mathrm{GH}, \mathrm{MH})$, and the level of agreement was calculated.

\section{Sample processing and analyses}

Serum was analyzed for sucrose using a previously validated gas chromatography-flame ionization detection (GC-FID) assay for quantifying sucrose in equine serum [42].

\section{Statistical analysis}

The overall diagnostic accuracy of blood sucrose for diagnosis of GL, GDL, SQL and CSL was assessed using receiver operator characteristics (ROC) curves and calculating the area under the curve (AUC). For each diagnostic criterion, sucrose concentration in blood at 45 and 90 min was compared with gastroscopy as the gold standard; and sensitivities (Se), specificities (Sp), positive predictive values (PPV) and negative predictive values (NPV) were calculated across a range of sucrose concentrations. Optimal cut-off values were then selected manually to optimize sensitivity and provide a practical threshold for practitioners in the field when screening horses for EGUS. Confidence intervals were set at $95 \%$ (95\% CI).

Inter-observer agreement was summarized as the percentage of perfect $(100 \%)$ agreements between observers for each diagnostic criterion, and a kappa coefficient (K) was calculated.

Statistical analyses were performed with $\mathrm{R}$ for Windows ${ }^{\circledR}$ version 3.0.2 .

\section{Results}

Horses

One hundred and one adult horses were accepted into the study; 59 mares, 4 stallions, and 38 geldings. Horses ranged from two to 22 years of age (median, 9.9 years). Body weight ranged from 400 to $683 \mathrm{~kg}$ (median, $518 \mathrm{~kg}$ ). Breeds included 37/101 Warmbloods, 25/101 Finnhorses, 34/101 Standardbreds, 3/101 Welsh Ponies, 1/101 Trakhener, and 1/101 Arab. Horses were used for a variety of purposes, including eventing, show jumping, dressage, trotting and general riding purposes. Fifty-three horses were demonstrating clinical signs suggestive of EGUS at the time of gastroscopy.

\section{Gastroscopy}

The overall prevalence of gastric lesions (ulcers or erosions) was $83 \%$. Lesions were most common in the glandular mucosae $(70 \%)$, followed by the squamous mucosae (53\%). Fifty eight percent of the horses had gastric lesions that were severe enough to be considered clinically significant i.e. requiring treatment. Squamous lesions were most frequently observed in the region of the cardia and along the lesser curvature of the stomach adjacent to the margo plicatus; and consisted primarily of small single ulcers characteristic of EGUS severity score $\leq 2$. Glandular lesions were exclusively observed around the pylorus and consisted primarily of focal raised hemorrhagic or fibrinous lesions.

\section{Sucrose permeability}

All horses tolerated sucrose permeability testing and no adverse effects were noted following administration of the sucrose solution. On analysis of the serum samples, all horses demonstrated an increase in serum sucrose concentration over time, with peak serum sucrose concentrations occurring $90 \mathrm{~min}$ after administration of the sucrose solution.

\footnotetext{
${ }^{4}$ R Foundation for Statistical Computing, Vienna, Austria.
} 
The mean $\pm \mathrm{SD}$ serum sucrose concentration at $45 \mathrm{~min}$ was $6.85 \pm 4.90 \mu \mathrm{mol} / \mathrm{l}$ for normal horses $(\mathrm{n}=17) ; 9.66 \pm 9.16 \mu \mathrm{mol} / \mathrm{l}$ for horses with $\mathrm{GL}(\mathrm{n}=84)$; $9.44 \pm 9.27 \mu \mathrm{mol} / \mathrm{l}$ for horses with GDL $(\mathrm{n}=71)$; $10.56 \pm 8.66 \mu \mathrm{mol} / \mathrm{l}$ for horses with SQL $(\mathrm{n}=54)$; and $10.43 \pm 9.22 \mu \mathrm{mol} / \mathrm{l}$ for horses with CSL $(\mathrm{n}=59)$. The mean $\pm \mathrm{SD}$ serum sucrose concentration at $90 \mathrm{~min}$ was $7.22 \pm 4.65 \mu \mathrm{mol} / \mathrm{l}$ for normal horses $(\mathrm{n}=17)$; $10.29 \pm 8.12 \mu \mathrm{mol} / \mathrm{l}$ for horses with GL $(\mathrm{n}=84)$; $9.86 \pm 7.54 \mu \mathrm{mol} / \mathrm{l}$ for horses with GDL $(\mathrm{n}=71)$; $11.53 \pm 8.17 \mu \mathrm{mol} / \mathrm{l}$ for horses with SQL $(\mathrm{n}=54)$; and $11.24 \pm 8.55 \mu \mathrm{mol} / \mathrm{l}$ for horses with CSL $(\mathrm{n}=59)$.

Diagnostic accuracy of blood sucrose for diagnosis of EGUS ROC curves for each diagnostic criterion at 45 and 90 min after sucrose administration are illustrated in Figs. 1 and 2.

\section{Gastric lesions}

The AUC $\pm 95 \%$ CI for blood sucrose concentration when used to distinguish between normal horses and horses with GL at 45 and 90 min was 0.59 (0.44-0.74) and $0.62(0.47-0.76)$ respectively. Sucrose concentrations of $4.61 \mu \mathrm{mol} / \mathrm{l}$ at $45 \mathrm{~min}$ and $4.57 \mu \mathrm{mol} / \mathrm{l}$ at $90 \mathrm{~min}$ were selected as the optimal cut-offs for discriminating between normal horses and horses with GL. The Se, Sp, PPV and NPV of blood sucrose at 45 and $90 \mathrm{~min}$ for diagnosis of GL using the selected cut-off values are depicted in Table 1.

\section{Glandular lesions}

The AUC $\pm 95 \%$ CI for blood sucrose concentration when used to distinguish between normal horses and horses with GDL at 45 and 90 min was $0.51(0.39-0.64)$ and $0.53(0.40-0.66)$ respectively. Sucrose concentrations of $5.80 \mu \mathrm{mol} / \mathrm{l}$ at $45 \mathrm{~min}$ and $6.05 \mu \mathrm{mol} / \mathrm{l}$ at $90 \mathrm{~min}$ were selected as the optimal cut-offs for discriminating between normal horses and horses with GDL. The Se, Sp, PPV and NPV of blood sucrose at 45 and $90 \mathrm{~min}$ for diagnosis of GDL using the selected cut-off values are depicted in Table 2.

\section{Squamous lesions}

The AUC for blood sucrose concentration when used to distinguish between normal horses and horses with SQL at 45 and $90 \mathrm{~min}$ was $0.65(0.55-0.76)$ and 0.68 (0.58-0.79) respectively. Sucrose concentrations of $7.86 \mu \mathrm{mol} / \mathrm{l}$ at $45 \mathrm{~min}$ and $8.24 \mu \mathrm{mol} / \mathrm{l}$ at $90 \mathrm{~min}$ were selected as the optimal cut-offs for discriminating between normal horses and horses with SQL. The Se, Sp, PPV and NPV of blood sucrose at 45 and 90 min for diagnosis of SQL using the selected cut-off values are depicted in Table 3.

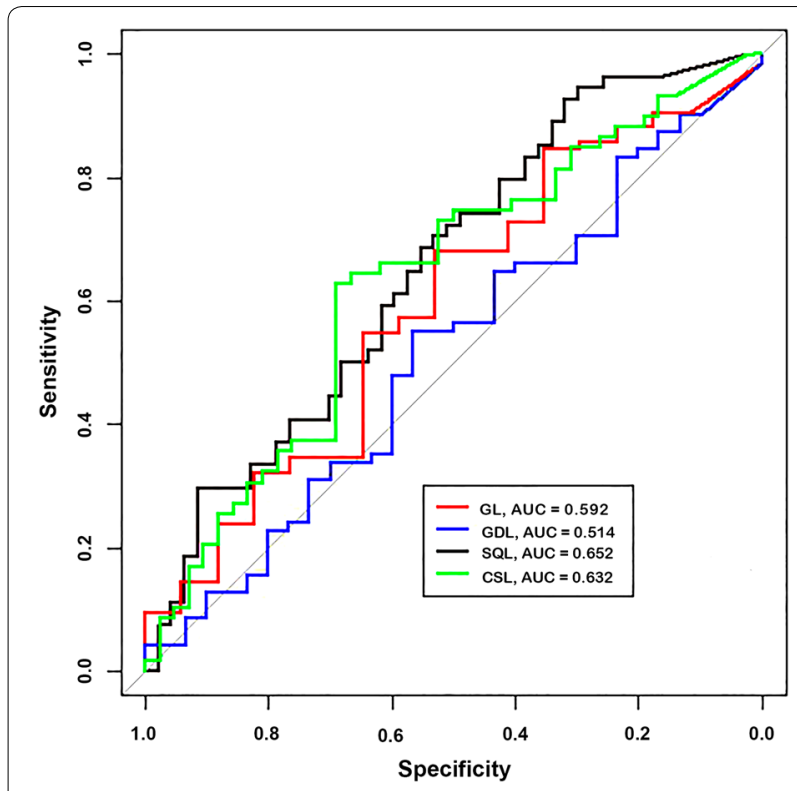

Fig. 1 ROC curves for blood sucrose concentration when used to distinguish between normal horses and horses with GL, GDL, SQL and CSL at $45 \mathrm{~min}$ after administration of $1 \mathrm{~g} / \mathrm{kg}$ of sucrose via nasogastric intubation. AUC area under the curve

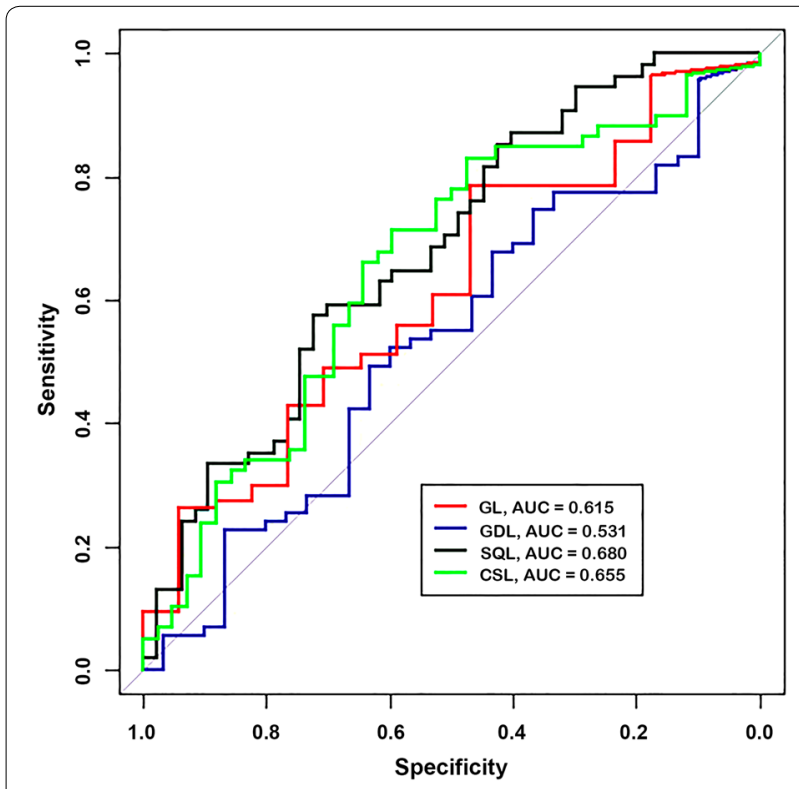

Fig. 2 ROC curves for blood sucrose concentration when used to distinguish between normal horses and horses with GL, GDL, SQL and CSL at 90 min after administration of $1 \mathrm{~g} / \mathrm{kg}$ of sucrose via nasogastric intubation. AUC area under the curve

\section{Clinically significant gastric lesions}

The AUC for blood sucrose concentration when used to distinguish between normal horses and horses with CSL 
Table 1 Sensitivity, specificity, positive and negative predictive values of blood sucrose for diagnosis of GL in horses after administration of $1 \mathbf{g} / \mathbf{k g}$ of sucrose via nasogastric intubation

\begin{tabular}{|c|c|c|c|c|c|c|c|}
\hline Time of sampling (min) & Cut-off $(\mu \mathrm{mol} / \mathrm{l})$ & Disease present & Disease absent & $\begin{array}{l}\mathrm{Sp}(\%) \\
95 \% \mathrm{Cl}\end{array}$ & $\begin{array}{l}\text { Se (\%) } \\
95 \% \mathrm{Cl}\end{array}$ & $\begin{array}{l}\text { NPV (\%) } \\
95 \% \mathrm{Cl}\end{array}$ & $\begin{array}{l}\text { PPV (\%) } \\
95 \% \mathrm{Cl}\end{array}$ \\
\hline \multirow[t]{2}{*}{45} & 4.61 & 84 & 17 & 52.9 & 67.9 & 25.0 & 87.7 \\
\hline & & & & $28-77$ & $57-78$ & $12-42$ & $77-95$ \\
\hline \multirow[t]{2}{*}{90} & 4.57 & 84 & 17 & 47.1 & 78.6 & 30.8 & 88.0 \\
\hline & & & & $23-72$ & $68-87$ & $14-52$ & 78-94 \\
\hline
\end{tabular}

GL gastric lesions, Se sensitivity, Sp specificity, NPV negative predictive value, $P P V$ positive predictive value, $95 \%$ CI $95 \%$ confidence intervals

Table 2 Sensitivity, specificity, positive and negative predictive values of blood sucrose for diagnosis of GDL in horses after administration of $1 \mathrm{~g} / \mathbf{k g}$ of sucrose via nasogastric intubation

\begin{tabular}{|c|c|c|c|c|c|c|c|}
\hline \multirow[t]{2}{*}{ Time of sampling ( $\mathrm{min}$ ) } & \multirow[t]{2}{*}{ Cut-off $(\mu \mathrm{mol} / \mathrm{l})$} & \multirow[t]{2}{*}{ Disease present } & \multirow[t]{2}{*}{ Disease absent } & \multirow{2}{*}{$\begin{array}{l}\mathrm{Sp}(\%) \\
95 \% \mathrm{Cl}\end{array}$} & \multirow{2}{*}{$\begin{array}{l}\text { Se (\%) } \\
95 \% \mathrm{Cl}\end{array}$} & \multirow{2}{*}{$\begin{array}{l}\text { NPV (\%) } \\
95 \% \mathrm{Cl}\end{array}$} & \multirow{2}{*}{$\begin{array}{l}\text { PPV (\%) } \\
95 \% \mathrm{Cl}\end{array}$} \\
\hline & & & & & & & \\
\hline \multirow[t]{2}{*}{45} & 5.80 & 71 & 31 & 48.1 & 50.7 & 30.0 & 69.2 \\
\hline & & & & $30-67$ & $39-63$ & $18-45$ & $55-81$ \\
\hline \multirow[t]{2}{*}{90} & 6.05 & 71 & 31 & 43.3 & 66.2 & 35.1 & 73.4 \\
\hline & & & & $26-63$ & $54-77$ & $20-53$ & $61-84$ \\
\hline
\end{tabular}

GL gastric lesions, Se sensitivity, Sp specificity, NPV negative predictive value, $P P V$ positive predictive value, $95 \%$ CI 95\% confidence intervals

Table 3 Sensitivity, specificity, positive and negative predictive values of blood sucrose for diagnosis of SQL in horses after administration of $1 \mathrm{~g} / \mathbf{k g}$ of sucrose via nasogastric intubation

\begin{tabular}{|c|c|c|c|c|c|c|c|}
\hline \multirow[t]{2}{*}{ Time of sampling ( $\mathrm{min}$ ) } & \multirow[t]{2}{*}{ Cut-off $(\mu \mathrm{mol} / \mathrm{l})$} & \multirow[t]{2}{*}{ Disease present } & \multirow[t]{2}{*}{ Disease absent } & Sp (\%) & Se (\%) & NPV (\%) & PPV (\%) \\
\hline & & & & $95 \% \mathrm{Cl}$ & $95 \% \mathrm{Cl}$ & $95 \% \mathrm{Cl}$ & $95 \% \mathrm{Cl}$ \\
\hline \multirow[t]{2}{*}{45} & 7.86 & 54 & 47 & 68.1 & 50.0 & 54.2 & 64.3 \\
\hline & & & & $53-81$ & $36-64$ & $41-67$ & $48-79$ \\
\hline \multirow[t]{2}{*}{90} & 8.24 & 54 & 47 & 72.3 & 57.4 & 59.7 & 70.5 \\
\hline & & & & $57-84$ & $43-71$ & $46-72$ & $55-83$ \\
\hline
\end{tabular}

SQL squamous lesions, Se sensitivity, Sp specificity, NPV negative predictive value, PPV positive predictive value, 95\% Cl 95\% confidence intervals

Table 4 Sensitivity, specificity, positive and negative predictive values of blood sucrose for diagnosis of CSL in horses after administration of $1 \mathrm{~g} / \mathbf{k g}$ of sucrose via nasogastric intubation

\begin{tabular}{|c|c|c|c|c|c|c|c|}
\hline \multirow[t]{2}{*}{ Time of sampling ( $\mathrm{min}$ ) } & \multirow[t]{2}{*}{ Cut-off $(\mu \mathrm{mol} / \mathrm{l})$} & \multirow[t]{2}{*}{ Disease present } & \multirow[t]{2}{*}{ Disease absent } & \multirow{2}{*}{$\begin{array}{l}\mathrm{Sp} \mathrm{( \% )} \\
95 \% \mathrm{Cl}\end{array}$} & \multirow{2}{*}{$\begin{array}{l}\text { Se (\%) } \\
95 \% \mathrm{CI}\end{array}$} & \multirow{2}{*}{$\begin{array}{l}\text { NPV (\%) } \\
95 \% \mathrm{Cl}\end{array}$} & \multirow{2}{*}{$\begin{array}{l}\text { PPV (\%) } \\
95 \% \mathrm{CI}\end{array}$} \\
\hline & & & & & & & \\
\hline \multirow[t]{2}{*}{45} & 4.61 & 59 & 42 & 50.0 & 74.6 & 58.3 & 67.7 \\
\hline & & & & $34-66$ & $62-85$ & $41-75$ & $55-79$ \\
\hline \multirow[t]{2}{*}{90} & 5.87 & 59 & 42 & 52.4 & 76.3 & 61.1 & 69.2 \\
\hline & & & & $36-68$ & $63-86$ & $44-77$ & $57-80$ \\
\hline
\end{tabular}

CSL clinically significant lesions, Se sensitivity, Sp specificity, NPV negative predictive value, $P P V$ positive predictive value, $95 \%$ Cl 95\% confidence intervals

at 45 and 90 min was $0.63(0.52-0.74)$ and $0.66(0.55-$ $0.77)$ respectively. Sucrose concentrations of $4.61 \mu \mathrm{mol} / \mathrm{l}$ at $45 \mathrm{~min}$ and $5.87 \mu \mathrm{mol} / \mathrm{l}$ at $90 \mathrm{~min}$ were selected as the optimal cut-offs for discriminating between normal horses and horses with clinically significant lesions. The Se, Sp, PPV and NPV of blood sucrose at 45 and $90 \mathrm{~min}$ for diagnosis of CSL using the selected cut-off values are depicted in Table 4.

Inter-observer agreement

When asked to answer if each horse has (1) gastric lesions; (2) glandular lesions; (3) squamous lesions; and 
(4) clinically significant gastric lesions, perfect agreement between-observers within the 101 sets of observations was achieved on average, in $83 \%(\mathrm{~K}=0.50 ; P<0.0001$; 95\% CI $0.24-0.76) ; 78 \%(\mathrm{~K}=0.57 ; P<0.0001 ; 95 \%$ CI 0.39-0.75); 74\% (K=0.65; $P<0.0001 ; 95 \%$ CI 0.53-0.77); and $75 \%(\mathrm{~K}=0.62 ; P<0.0001 ; 95 \% \mathrm{CI} 0.48-0.75)$ of the cases respectively.

\section{Discussion}

The objective of this study was to validate the sucrose blood test as a screening test for EGUS in adult horses by determining its performance characteristics in a large group of horses with and without naturally occurring gastric disease. ROC curve analysis was used to visually demonstrate the cut-off dependency of the test across a range of sucrose concentrations and to provide an estimate of the overall diagnostic accuracy of the test that is independent of specific cut-off values or prevalence of gastric lesions in the study population. For this study, ROC curves of true positive rates (Se) against false positive rates (1-Sp) were plotted using blood sucrose concentrations from normal horses, and horses with GL, GDL, SQL and CSL at 45 and 90 min after administration of sucrose (Figs. 1, 2). The AUC's in each plot represents a summary of the overall diagnostic accuracy of the test by combining accuracy over a range of cut-offs, with a value approaching 1.0 indicating perfect discrimination and 0.5 representing zero discrimination. Using an arbitrary guideline, the AUC can be used to distinguish between a non-informative (AUC $=0.5)$; less accurate $(0.5<$ AUC $\leq 0.7)$; moderately accurate $(0.7<$ AUC $\leq 0.9)$; highly accurate $(0.9<$ AUC $<1)$; and perfect test $(A U C=1)$ [43]. Depending upon the lesion type and time of sampling, the AUC for the blood sucrose test ranged from 0.51 to 0.68 , indicating that blood sucrose concentration is poor at discriminating between normal horses and horses with EGUS and is therefore not considered to be a very accurate test.

Because the AUC summarizes the ROC curve as a whole, and therefore attributes the same weighting to both relevant and irrelevant parts of the curve [44], cutoff values were inserted on the continuous scale of test results that allowed calculation of Se and Sp for horses with GL, GDL, SQL and CSL at each time point. Using the selected cut-offs, the Se and Sp of the blood sucrose test for detecting the presence or absence of EGUS was low (Tables 1, 2, 3, 4), confirming the poor diagnostic accuracy of the test in this study population.

It is not immediately evident why the sucrose blood test has a poor diagnostic accuracy in adult horses despite previous literature to suggest otherwise [21-23]. In this study, there was a predominance of glandular lesions (70\%) whereas in previous studies, sucrose permeability was assessed primarily on horses with squamous lesions; and it may be that there are fundamental differences in the permeability of the sucrose molecule between the glandular and squamous epithelium. It has been found that gap junctional intercellular communication (GJIC) plays an important role in the gastric mucosal defense system, and loss of GJIC is associated with ulcer formation. A recent study demonstrated the presence of specific gap junctions in the glandular mucosa of the equine stomach, however these gap junctions were absent in the squamous mucosa of the stomach [45]. This suggests that there are significant differences in the permeation pathway of the glandular vs. the squamous epithelium which may explain (in part) why in this study population, with a predominace of glandular ulcers, the sucrose blood test had a poorer diagnostic accuracy than expected. Furthermore, glandular lesions are often smaller in crosssectional area and are usually not ulcerative per se, but rather erosive or may even consist of intact mucosa with hyperemia [1]. In such cases, it is possible that sucrose is less likely to permeate in quantities large enough to appreciate differences between affected and unaffected horses, although this has yet to be substantiated.

The authors do recognize however, that the sensitivity and specificity for squamous lesions was also poor, albeit less so than for glandular ulcers. Another factor to consider therefore, is the fact that in this particular study, very few of the squamous lesions were extensive or demonstrated areas of apparent deep ulceration characteristic of EGUS severity score $\geq 3$ [1]. It is therefore possible that in such cases, the total surface area for sucrose permeation was too small to differentiate between affected and unaffected horses. Based on this premise, re-analysis of the data using a scoring system that takes into account not only the severity of the lesion, but also the number of lesions should be considered [46].

Alternatively, the validity of the gold standard itself can be questioned. It may be that the sucrose test is too sensitive and may detect slight and clinically insignificant mucosal damage that cannot be seen on endoscopy, thus limiting its use in clinical decision-making regarding gastric ulceration [33]. We postulate that sucrose permeability is in fact an accurate representation of the true mucosal integrity of the stomach based on a number of previous publications documenting its effectiveness in both humans and other species $[35,36,38,47]$; and that assessment via endoscopy is under- or overestimating the severity or depth of gastric lesions. This is based on the fact that assessment of lesion severity (and even the presence or absence of lesions) using gastroscopy is subjective, and agreement between observers for endoscopic diagnosis is notoriously poor, particularly if they are inexperienced [48, 
49]. Furthermore, it has been demonstrated that there is a poor correlation between endoscopic assessment of gastric ulcers ante mortem and histological appearance at necropsy [46, 50]. Because of these limitations, an attempt was made in this study to determine if the gold standard was reproducible between-observers. All assessments made by the observer were compared with assessments made by two other board certified internists that have experience with gastroscopy, and the level of agreement for each outcome was determined. Agreement was moderate [51], but still unacceptably low, and it is possible that in the hands of different observers, the diagnostic accuracy of the test will vary. Considering these limitations, it is the authors' opinion that histopathology rather than endoscopy should be utilized as a gold standard for comparison in future gastric permeability studies. Alternatively, Bayesian statistical approaches that are used for evaluation of diagnostic tests in the absence of a gold standard test should be considered [52].

The choice to include the severity of gastric ulceration in the study was based on the premise that the sucrose blood test would be able to differentiate between severe and less severe lesions, enabling practitioners to select cases for treatment based upon the outcome of the test. Unfortunately there are no grading systems that can be used interchangeably for horses with both ESGD and EGGD [53], and so the authors elected to use the concept of a 'clinically significant gastric lesion' as a proxy indicator of ulcer severity, where clinically significant lesions were defined as lesions that the observer would consider severe enough to warrant treatment if seen in a clinical case. While the authors recognize that this is not a perfect solution, as clinicians will usually use both gastroscopic appearance of lesions in combination with the clinical history to determine clinically significance, the authors believe that this proxy is the best possible compromise. While a scoring system (e.g. EGUS 0-4) would have been more objective, the fact that it cannot be used for EGGD makes it impossible to be used in this study. In future, assessment of both clinical and endoscopic outcomes when determining the diagnostic accuracy of the sucrose test is recommended.

When conducting a validation study to determine the diagnostic accuracy of a test, it is essential that the study include an appropriate spectrum of subjects which is representative of the population for which the test is intended. We aimed to determine the diagnostic accuracy of the sucrose blood test as a screening test for EGUS in adult horses and therefore we selected horses used for a wide spectrum of activities, ranging from dressage to racing. Eighty four percent of the horses in the study population had gastric lesions, which is similar to previously reported prevalence data for this geographical region [14]. Unfortunately, there was a limited spectrum of disease in the study population, with a predominance of small single lesions and a noticeable absence of extensive lesions with areas of apparent deep ulceration. As discussed earlier, this has the potential to skew the results by virtue of the fact that permeability of sucrose is directly proportional to the surface area of the damaged gastric mucosa available for permeation. An additional limitation of the study was the fact that that a proportion of the horses in this study (58/101) showed no clinical signs of gastric ulceration at the time of sucrose testing. There is currently little evidence to suggest a direct cause-and-effect relationship between clinical signs of EGUS and the presence, severity or location of gastric ulcers in adult horses [1] and, therefore, it is possible that the diagnostic accuracy of the sucrose test would be improved when testing a population of horses that were all demonstrating clinical signs at the time of gastroscopy.

\section{Conclusions}

Blood sucrose was neither a sensitive nor specific test for detecting EGUS in this population of adult horses with naturally occurring disease. This study included both horses with and without clinical signs of gastric ulceration. Further studies aimed at evaluating the performance characteristics of the test in a selected population of horses demonstrating clinical signs consistent with EGUS may be warranted. Given the limitations of endoscopy, due consideration should also be given to alternative methods for comparison of blood sucrose with a gold standard (Additional file 1).

\section{Additional file}

Additional file 1. Estimation of the sensitivity, specificity and predictive values of blood sucrose as a screening test for EGUS in adult horses using Bayesian latent class methods.

\section{Abbreviations}

BW: body weight; EGUS: equine gastric ulcer syndrome; GL: gastric lesion; GDL: glandular lesions; SQL: squamous lesion; CSL: clinically significant lesion; GCFID: gas chromatography-flame ionization detection; ROC: receiver operator characteristic; AUC: area under the curve; Se: sensitivity; Sp: specificity; PPV: positive predictive value; NPV: negative predictive value; $95 \% \mathrm{Cl}$ : 95\% confidence intervals; SD: standard deviation.

\section{Authors' contributions}

$\mathrm{MH}$ participated in the hypothesis generation, study design, organizing and acquisition of data, interpreting and analyzing the results, and drafting the manuscript. BS and GH participated in the acquisition of data, interpreting and analyzing the results, and critical revision of the manuscript. RMT participated in the study design, interpreting the results, and critical revision of the manuscript. All authors read and approved the final manuscript. 


\begin{abstract}
Author details
1 Department of Equine and Small Animal Medicine, Faculty of Veterinary Medicine, University of Helsinki, Helsinki, Finland. ${ }^{2}$ School of Veterinary Sciences, University of Queensland, Brisbane, Australia. ${ }^{3}$ School of Veterinary Medicine and Science, University of Nottingham, Nottingham, UK. ${ }^{4}$ Department of Companion Animal Clinical Studies, Faculty of Veterinary Science, University of Pretoria, Onderstepoort, South Africa.
\end{abstract}

\section{Acknowledgements}

The authors would like to thank professors Allen Rousell, Sandy Love, Satu Sankari, Noah Cohen and Anna-Maija Virtala for their support, guidance and vision; Kaisa Aaltonen and Anne Sjöhölm for their technical assistance; and Jouni Junnila and Geoffry Fosgate for their assistance with the statistical analysis.

\section{Competing interests}

The authors declare that they have no competing interests.

\section{Availability of data and materials}

The datasets during and/or analyzed during the current study are available from the corresponding author on reasonable request.

\section{Ethics approval}

The experimental work that formed the basis of this study was evaluated and accepted by the National Animal Experiment Board of Finland [Eläinkoelautakunta-ELLA, eläinkoeluvan numero jota koskee: ESAVI-201006858/Ym-23]. Informed consent from the owner, or the trainer acting as an agent for the owner, was obtained at the time of enrolment to the study.

Received: 20 September 2016 Accepted: 5 March 2017 Published online: 11 March 2017

\section{References}

1. Sykes BW, Hewetson M, Hepburn RJ, Luthersson N, Tamzali Y. European College of Equine Internal Medicine Consensus Statement-equine gastric ulcer syndrome in adult horses. J Vet Intern Med. 2015;29:1288-99.

2. Murray MJ, Schusser GF, Pipers FS, Gross SJ. Factors associated with gastric lesions in thoroughbred racehorses. Equine Vet J. 1996;28:368-74.

3. Begg LM, O'Sullivan CB. The prevalence and distribution of gastric ulceration in 345 racehorses. Aust Vet J. 2003;81:199-201.

4. Vatistas NJ, Snyder JR, Carlson G, Johnson B, Arthur RM, Thurmond M, et al. Cross-sectional study of gastric ulcers of the squamous mucosa in thoroughbred racehorses. Equine Vet J. 1999;29:34-9.

5. Sykes BW, Sykes KM, Hallowell GD. A comparison of three doses of omeprazole in the treatment of equine gastric ulcer syndrome: a blinded, randomised, dose-response clinical trial. Equine Vet J. 2015;47:285-90.

6. Rabuffo TS, Orsini JA, Sullivan E, Engiles J, Norman T, Boston R. Associations between age or sex and prevalence of gastric ulceration in Standardbred racehorses in training. J Am Vet Med Assoc. 2002;221:1156-9.

7. Dionne RM, Vrins A, Doucet MY, Pare J. Gastric ulcers in standardbred racehorses: prevalence, lesion description, and risk factors. J Vet Intern Med. 2003;17:218-22

8. Jonsson H, Egenvall A. Prevalence of gastric ulceration in Swedish Standardbreds in race training. Equine Vet J. 2006;38:209-13.

9. Nieto JE, Snyder JR, Beldomenico P, Aleman M, Kerr JW, Spier SJ. Prevalence of gastric ulcers in endurance horses-a preliminary report. Vet J. 2004;167:33-7.

10. Tamzali Y, Marguet C, Priymenko N, Lyazrhi F. Prevalence of gastric ulcer syndrome in high-level endurance horses. Equine Vet J. 2011:43:141-4.

11. McClure SR, Glickman LT, Glickman NW. Prevalence of gastric ulcers in show horses. J Am Vet Med Assoc. 1999;215:1130-3.

12. Hartmann AM, Frankeny RL. A preliminary investigation into the association between competition and gastric ulcer formation in non-racing performance horses. J Equine Vet Sci. 2003;23:560-1.

13. le Jeune SS, Nieto JE, Dechant JE, Snyder JR. Prevalence of gastric ulcers in Thoroughbred broodmares in pasture: a preliminary report. Vet J. 2009;181:251-5.
14. Luthersson N, Nielsen KH, Harris P, Parkin TD. The prevalence and anatomical distribution of equine gastric ulceration syndrome (EGUS) in 201 horses in Denmark. Equine Vet J. 2009;41:619-24.

15. Chameroy KA, Nadeau JA, Bushmich SL, Dinger JE, Hoagland TA, Saxton AM. Prevalence of non-glandular gastric ulcers in horses involved in a university riding program. J Equine Vet Sci. 2006;26:207-11.

16. Andrews FM, Bernard WV, Byars TD, Cohen ND, Divers TJ, MacAllister $\mathrm{CG}$, et al. Recommendations for the diagnosis and treatment of equine gastric ulcer syndrome (EGUS). Equine Vet Educ. 1999;1:122-34.

17. Bell RJW, Kingston JK, Mogg TD, Perkins NR. The prevalence of gastric ulceration in racehorses in New Zealand. N Z Vet J. 2007:55:13-8.

18. Andrews FM, Nadeau JA. Clinical syndromes of gastric ulceration in foals and mature horses. Equine Vet J. 1999;31:30-3.

19. Murray MJ, Grodinsky C, Anderson CW, Radue PF, Schmidt GR. Gastric ulcers in horses: a comparison of endoscopic findings in horses with and without clinical signs. Equine Vet J. 1989;7:68-72.

20. Murray MJ, Murray CM, Sweeney HJ, Weld J, Digby NJ, Stoneham SJ. Prevalence of gastric lesions in foals without signs of gastric disease: an endoscopic survey. Equine Vet J. 1990;22:6-8.

21. Hewetson M, Cohen ND, Love S, Buddington RK, Holmes W, Innocent GT, et al. Sucrose concentration in blood: a new method for assessment of gastric permeability in horses with gastric ulceration. J Vet Intern Med. 2006;20:388-94.

22. O'Conner MS, Steiner JM, Roussel AJ, Williams DA, Meddings JB, Pipers F, et al. Evaluation of urine sucrose concentration for detection of gastric ulcers in horses. Am J Vet Res. 2004;65:31-9.

23. D'Arcy-Moskwa E, Noble GK, Weston LA, Boston R, Raidal SL. Effects of meloxicam and phenylbutazone on equine gastric mucosal permeability. J Vet Intern Med. 2012;26:1494-9.

24. Pantzar N, Westrom BR, Luts A, Lundin S. Regional small-intestinal permeability in vitro to different-sized dextrans and proteins in the rat. Scand J Gastroenterol. 1993;28:205-11.

25. Gryboski JD, Thayer WR Jr, Gabrielson IW, Spiro HM. Disacchariduria in gastrointestinal disease. Gastroenterology. 1963;45:633-7.

26. Lindemann B, Solomon AK. Permeability of luminal surface of intestinal mucosal cells. J Gen Physiol. 1962;45:801-10.

27. Roberts MC. Carbohydrate digestion and absorption studies in the horse. Res Vet Sci. 1975;18:64-9.

28. Roberts MC. Carbohydrate digestion and absorption in the equine small intestine. J S Afr Vet Assoc. 1975;46:19-27.

29. Dyer J, Fernandez-Castano Merediz E, Salmon KS, Proudman CJ, Edwards GB, Shirazi-Beechey SP. Molecular characterisation of carbohydrate digestion and absorption in equine small intestine. Equine Vet J. 2002;34:349-58.

30. Vettorazzi G, MacDonald I. Sucrose: nutritional and safety aspects. New York: Springer; 1988. p. 35-8.

31. Keith NM, Power MH. The urinary excretion of sucrose and its distribution in the blood after intravenous injection into normal men. Am J Physiol. 1937;120:203-11.

32. Davies NM, Corrigan BW, Jamali F. Sucrose urinary excretion in the rat measured using a simple assay: a model of gastroduodenal permeability. Pharm Res. 1995;12:1733-6.

33. Erlacher L, Wyatt J, Pflugbeil S, Koller M, Ullrich R, Vogelsang $H$, et al. Sucrose permeability as a marker for NSAID-induced gastroduodenal injury. Clin Exp Rheumatol. 1998;16:69-71.

34. Goodgame RW, Malaty HM, el-Zimaity HM, Graham DY. Decrease in gastric permeability to sucrose following cure of Helicobacter pylori infection. Helicobacter. 1997;2:44-7.

35. Meddings JB, Kirk D, Olson ME. Noninvasive detection of nonsteroidal anti-inflammatory drug-induced gastropathy in dogs. Am J Vet Res. 1995:56:977-81.

36. Meddings JB, Sutherland LR, Byles NI, Wallace JL. Sucrose: a novel permeability marker for gastroduodenal disease. Gastroenterology. 1993;104:1619-26.

37. Meddings JB, Wallace JL, Sutherland LR. Sucrose permeability: a novel means of detecting gastroduodenal damage noninvasively. Am J Ther. 1995;2:843-9.

38. Sutherland LR, Verhoef M, Wallace JL, Van Rosendaal G, Crutcher R, Meddings JB. A simple, non-invasive marker of gastric damage: sucrose permeability. Lancet. 1994;343:998-1000. 
39. Hopkins AM, McDonnell C, Breslin NP, O'Morain CA, Baird AW. Omeprazole increases permeability across isolated rat gastric mucosa pre-treated with an acid secretagogue. J Pharm Pharmacol. 2002;54:341-7.

40. Jenkins AP, Trew DR, Crump BJ, Nukajam WS, Foley JA, Menzies IS, et al. Do non-steroidal anti-inflammatory drugs increase colonic permeability? Gut. 1991;32:66-9.

41. Murray MJ, Eichorn ES. Effects of intermittent feed deprivation, intermittent feed deprivation with ranitidine administration, and stall confinement with ad libitum access to hay on gastric ulceration in horses. Am J Vet Res. 1996;57:1599-603.

42. Hewetson M, Aaltonen K, Tulamo RM, Sankari S. Development and validation of a gas chromatography-flame ionization detection method for quantifying sucrose in equine serum. J Vet Diagn Invest. 2014;26:232-9.

43. Swets JA. Measuring the accuracy of diagnostic systems. Science. 1988;240:1285-93.

44. Greiner M, Pfeiffer D, Smith RD. Principles and practical application of the receiver-operating characteristic analysis for diagnostic tests. Prev Vet Med. 2000:45:23-41.

45. Fink C, Hembes T, Brehm R, Weigel R, Heeb C, Pfarrer C, et al. Specific localisation of gap junction protein connexin 32 in the gastric mucosa of horses. Histochem Cell Biol. 2006;125:307-13.

46. Andrews FM, Reinemeyer CR, McCracken MD, Blackford JT, Nadeau JA, Saabye L, et al. Comparison of endoscopic, necropsy and histology scoring of equine gastric ulcers. Equine Vet J. 2002;34:475-8.
47. Craven M, Chandler ML, Steiner JM, Farhadi A, Welsh E, Pratschke K, et al. Acute effects of carprofen and meloxicam on canine gastrointestinal permeability and mucosal absorptive capacity. J Vet Intern Med. 2007;21:917-23.

48. Amano Y, Ishimura N, Furuta K, Okita K, Masaharu M, Azumi T, et al. Interobserver agreement on classifying endoscopic diagnoses of nonerosive esophagitis. Endoscopy. 2006;38:1032-5.

49. Hyun YS, Han DS, Bae JH, Park HS, Eun CS. Interobserver variability and accuracy of high-definition endoscopic diagnosis for gastric intestinal metaplasia among experienced and inexperienced endoscopists. J Korean Med Sci. 2013;28:744-9.

50. Pietra M, Morini M, Perfetti G, Spadari A, Vigo P, Peli A. Comparison of endoscopy, histology, and cytokine mRNA of the equine gastric mucosa. Vet Res Commun. 2010;34(Suppl 1):S121-4.

51. Viera AJ, Garrett JM. Understanding interobserver agreement: the kappa statistic. Fam Med. 2005;37:360-3.

52. Toft N, Jorgensen $E$, Hojsgaard S. Diagnosing diagnostic tests: evaluating the assumptions underlying the estimation of sensitivity and specificity in the absence of a gold standard. Prev Vet Med. 2005;68:19-33.

53. Sykes BW, Jokisalo J, Hallowell GD. Evaluation of a commercial faecal blood test for the diagnosis 636 of gastric ulceration in Thoroughbred racehorses: a preliminary report. BMC Vet Res. 2014;9:10.

\section{Submit your next manuscript to BioMed Central and we will help you at every step:}

- We accept pre-submission inquiries

- Our selector tool helps you to find the most relevant journal

- We provide round the clock customer support

- Convenient online submission

- Thorough peer review

- Inclusion in PubMed and all major indexing services

- Maximum visibility for your research

Submit your manuscript at www.biomedcentral.com/submit

Biomed Central 